\title{
Apéndice \\ Facultad de Economía \\ Plan Estratégico de Investigación 2017-2027
}

\section{Introducción}

T a investigación, en la Universidad Santo Tomás de Aquino (USTA), namiento, al debate y a la búsqueda de soluciones de los problemas que afectan a la sociedad, para lo cual se inspira en el pensamiento de Tomás de Aquino, expresado en el lema institucional "facientes veritatem"; se orienta por la legislación nacional y por un marco normativo institucional propio que se desarrolla en el Estatuto Orgánico (USTA, 2002), el Proyecto Educativo Institucional -PEI (USTA, 2004), la Política Curricular (USTA, 2004), el Estatuto Docente (USTA, 2004), el Proyecto Investigativo Institucional -PROIN (USTA, 2005) y en otros documentos de la legislación interna; se constituye en una de las partes integrales de los Planes de Desarrollo Institucional.

Bajo ese marco normativo, y a través del Centro de Investigaciones Económicas Louis Joseph Lebret O. P., la Facultad de Economía formuló el Plan Estratégico de Investigación 2017-2020, encaminado a consolidar los grupos de investigación Economía y Humanismo y Salud Pública, y articular programas y proyectos de investigación en torno a cuatro líneas de investigación:

- Economía Pública y Social

- Economía Financiera

- Economía de las Organizaciones

- Economía de la Salud 
Este apéndice contiene en su orden los siguientes acápites:

- Política de investigación de la Facultad de Economía.

- La investigación en el Plan Integral Multicampus -PIM 20162027 y en el Plan General de Desarrollo 2016-2019.

- Fundamentos epistemológicos de la investigación en la Facultad de Economía.

- Líneas de investigación en la Facultad de Economía.

- Programas de Investigación.

- Estrategias de investigación.

\section{Política de investigación de la Facultad de Economía}

La naturaleza de los trabajos de investigación que realizan estudiantes y docentes en los programas de pregrado y posgrado en la Facultad de Economía, corresponden a dos tipos de investigación: la investigación formativa -orientada a fortalecer en los estudiantes competencias investigativas- y la investigación propiamente dicha -que desarrollan los grupos de investigación-, las cuales se desarrollan bajo un marco normativo institucional:

- El Estatuto Orgánico (2002, p. 19) establece que “... la Universidad, en cuanto generadora de conocimiento mediante la investigación y como transmisora del mismo a través de la docencia, considera la ciencia como un producto humano que debe preservar, custodiar, incrementar y difundir”.

- El Proyecto Educativo Institucional -PEI, señala que “... se investiga para producir nuevos saberes: establecer el estado de los saberes, interpretar, adaptar o prolongar saberes recibidos, producir formas eficaces de transmisión de saberes, todo eso cabe dentro del concepto de investigación” (p. 87).

El PEI destaca que la investigación supone un reconocimiento inicial de lo que se hace en las distintas profesiones y una reflexión profunda de para qué o para quiénes se hace. En esa medida, la investigación aplicada al servicio de la sociedad, se 
soporta en la identificación de problemas que a su vez generan una nueva dinámica en el proceso de formación, basado en problemas.

Y agrega: "Mediante la interdisciplinariedad, la USTA pretende que las distintas disciplinas y profesiones hallen estructuras comunes, que articulen sus investigaciones y conocimientos; exigencia de la complejidad de la vida concreta de las comunidades a las que la Universidad sirve" (p. 89). Con ello, se evidencia que la identificación de problemas y sus posibles soluciones no se resuelven exclusivamente con una perspectiva unidisciplinar, sino que, a partir de un conocimiento amplio y abierto de otras disciplinas, se obtienen elementos, conceptos y métodos que permiten la construcción del conocimiento integral.

- $\quad$ El Proyecto Investigativo Institucional -PROIN (2005), establece las políticas, principios y organización de la investigación en la Universidad Santo Tomás y plantea el modelo de investigación institucional, el cual parte del problema, el proyecto y las líneas medulares de investigación (LMI), las cuales “... se conceptualizan como los principios básicos articulados alrededor de un eje temático precisado por la institución o por una serie de elementos contextuales que responden a determinados problemas y apuntan o posibilitan la realización de proyectos investigativos" (p. 83).

Las líneas medulares de investigación (LMI) “... tienen por objetivo orientar el estudio de objetos y núcleos problemáticos que puedan ser abordados desde diferentes disciplinas del conocimiento, con el propósito de generar soluciones con criterios de inter y transdisciplinariedad...” (p. 83). La LMI que orienta la investigación en la Facultad de Economía es la línea Louis Joseph Lebret O. P., sobre economía y humanismo. El objeto de estudio de la línea medular es analizar el comportamiento de los modelos económicos y el desarrollo humano y con ella se articulan las líneas activas de investigación de la Facultad: economía pública y social, economía de las organizaciones, economía financiera y economía de la salud. 
La Universidad Santo Tomás promueve la construcción de una comunidad investigativa, a través de la estructura de gestión desde la Unidad de Investigación (UI) de la Universidad y la propuesta del Modelo Investigativo de la Universidad incluida en el PROIN que, de manera sistémica y recursiva y mediante la adecuada armazón de un soporte académico y técnico, facilita la acción investigativa en cada uno de los programas académicos, proponiendo la investigación como la explicitación del conocimiento, tanto teórica como práctica de las disciplinas, integrando de manera continua y pertinente la investigación con la docencia y la extensión universitaria. El modelo investigativo implícito en el modelo pedagógico (USTA, 2010) y en los documentos institucionales de la USTA mencionados arriba, se aprecia en la gráfica A1.

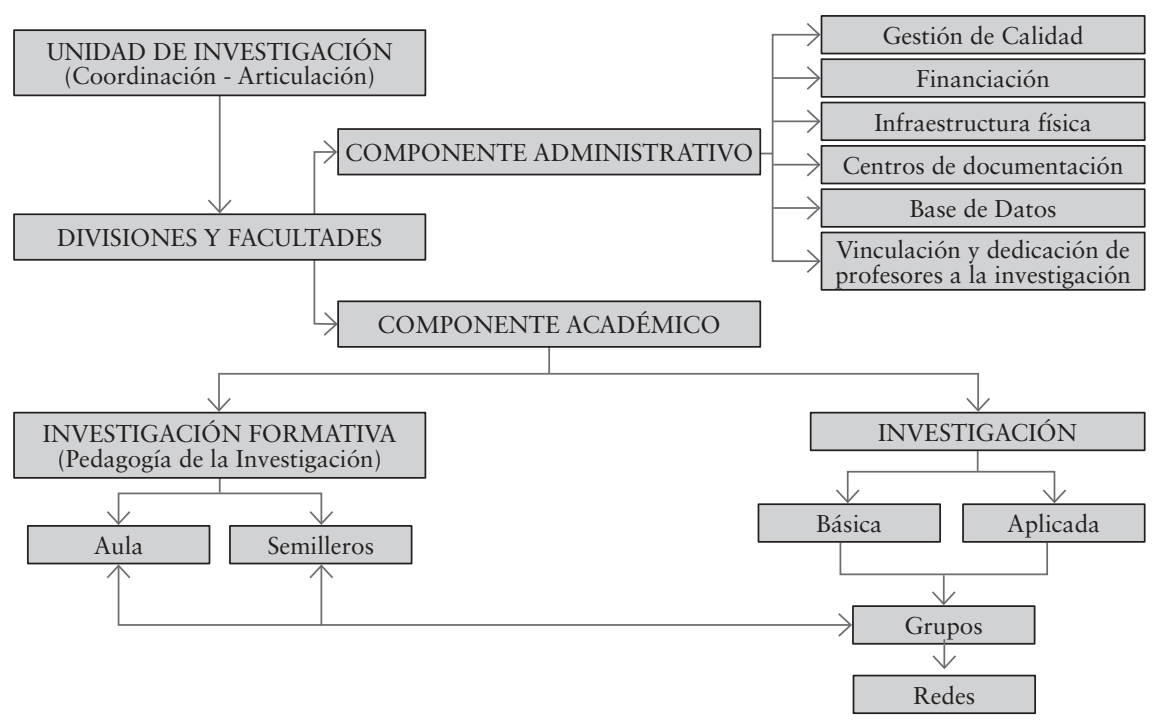

Gráfica A1. Modelo de gestión de la investigación en la USTA

\section{La investigación en el Plan Integral Multicampus -PIM- 2016-2027 y en el Plan General de Desarrollo 2016-2019}

El Plan Integral Multicampus (PIM) 2016-2027, define entre sus líneas de acción la Proyección Social e Investigación Pertinentes (línea 3). 
El PIM señala que la Universidad Santo Tomás busca "consolidarse como una institución multicampus, generadora de conocimiento, con visibilidad, impacto y reconocimiento mundial, incidiendo en la transformación de las realidades regionales y nacionales en ambientes sustentables de justicia y paz, respondiendo a los desafíos de la globalización, incorporándose de forma responsable a redes mundiales de conocimiento, contribuyendo a un país más solidario, equitativo, competitivo, y con mejor calidad de vida para todos sus habitantes".

En ese contexto, la investigación y la proyección social para la Universidad son pertinentes en la medida en que abordan y contribuyen a la solución de problemas relevantes de las regiones y del país de forma responsable, interdisciplinaria y con impacto social en el ámbito regional y nacional, que se potencian a través de convenios de cooperación y redes de conocimiento e innovación que permiten articularse a la dinámica mundial.

De la misma forma, la Universidad le apuesta a propuestas formativas en pregrado y posgrado que vinculen la proyección social con proyectos de investigación y con diseños curriculares pertinentes a las agendas de investigación nacionales e internacionales.

Dicha apuesta permitirá el establecimiento de capacidades científicas, sociales y la producción de conocimiento con altos estándares de calidad en la perspectiva misional, con el objetivo de aportar a la construcción del bien común y la persona humana, en la que los valores humanos enmarcados en la filosofía de santo Tomás de Aquino hacen parte estructural de su conformación: plenitud personal, libertad en situación, responsabilidad, solidaridad, justicia, paz y verdad.

Así mismo, se busca fortalecer el trabajo con las diferentes sedes, seccionales y la Vicerrectoría de Universidad Abierta y a Distancia (VUAD), mediante estrategias que permitan armonizar los planes de desarrollo regionales y aporten inter y transdisciplinariamente a la solución de problemas complejos, para lograr una articulación eficaz y sistemática con los procesos de docencia desde un enfoque diferencial y territorial, en el campo de la educación superior. 
Por su parte, el Plan General de Desarrollo 2016-2019 de la USTA precisa el alcance de la línea 3 de acción establecida en el PIM con el siguiente objetivo: Focalizar y articular la investigación y la proyección social de la USTA con visibilidad e impacto nacional y global. Este objetivo tiene a su vez cinco subobjetivos:

\section{a) Identificar los campos de acción a nivel nacional y regional de la USTÁ}

Acciones:

- Realizar diagnóstico institucional a partir del impacto de la investigación y de las estrategias de proyección social en la USTA.

- Definir los campos de acción nacionales y regionales para la USTA articulados a las funciones sustantivas.

- Desarrollar estrategias, programas y proyectos para la construcción de ambientes sustentables de justicia, paz y reconciliación.

- Evaluar la incidencia y el impacto de los programas, proyectos y acciones institucionales desarrolladas en la investigación y la proyección social en los campos de acción definidos.

\section{b) Garantizar que los programas y proyectos de proyección social se articulen con las demás funciones sustantivas, en concordancia con los campos de acción definidos}

Acciones:

- Potenciar a nivel nacional la cátedra de la paz / Seminario continuo de la paz para la comunidad.

- Definir los programas y proyectos de proyección social en los que la institución se debe concentrar, según los campos de acción.

- Implementar los programas y proyectos de proyección social.

- Verificar la articulación de las funciones sustantivas en los programas y proyectos implementados. 


\section{c) Establecer un sistema nacional de investigación multicampus que contribuya al posicionamiento y visibilidad nacional e internacional de la USTA}

Acciones:

- Diseñar un sistema nacional de investigación.

- Implementar el sistema nacional de investigación.

- Hacer seguimiento y evaluación al sistema nacional de investigación.

\section{d) Incrementar la producción investigativa con impacto regional, nacional e internacional}

Acciones:

- Establecer redes nacionales de investigación e innovación de carácter interdisciplinario que respondan a los campos de acción identificados.

- Realizar convocatorias internas y participar en convocatorias externas multicampus.

- Incrementar el desarrollo de proyectos de investigación multicampus, con recursos propios y con financiación externa.

- Consolidar el desarrollo de los procesos de investigación en posgrado, fomentando los procesos de investigación en pregrado.

- Desarrollar estrategias que permitan verificar la articulación de las funciones de docencia y proyección social en la producción investigativa de la USTA.

e) Aumentar de manera progresiva y sostenible la cooperación académica con otras instituciones nacionales e internacionales

Acciones:

- Evaluar la pertinencia de los convenios en orden al desarrollo institucional en la USTA. 
- Establecer convenios que faciliten la cooperación académica para el desarrollo de las funciones sustantivas.

- Promover la participación de la comunidad universitaria en los convenios activos.

- Establecer mecanismos de seguimiento y control para los convenios de cooperación académica en la USTA.

\section{Fundamentos epistemológicos de la investigación en la Facultad de Economía}

La Facultad de Economía de la Universidad Santo Tomás, “... se inscribe en la tradición del pensamiento económico convencional, específicamente en aquellos hitos que resaltan la dimensión social de los fenómenos de la asignación, la producción y la distribución (...), filón social que tiene en cuenta la teoría tomista del precio justo, se extiende desde la economía política clásica hasta la moderna economía política de la elección pública y el neoinstitucionalismo" ${ }^{1}$. Se subraya lo social con relación a lo público y a la presencia del Estado. Las relaciones Estado/mercado no son antinómicas. En la perspectiva social de la economía, el bien común o el bien-estar ${ }^{2}$, son categorías sustantivas y establecen el horizonte de las interacciones positivas y normativas de las relaciones Estado/mercado/comunidad.

\section{Ciencias económicas $v s$. realidad}

En las décadas recientes, se han manifestado con mayor vigor las aparentes contradicciones entre las demandas sociales crecientes -en contextos de mercados globalizados y asimétricos, brechas tecnológicas

1 Arcos O., Castillo B., Infante M., y Torres D., 2002. Programa de Investigación en Economía Social. Línea de Investigación: "Pobreza, Políticas Públicas y Equidad”. Universidad Santo Tomás, Facultad de Economía, Maestría en Ciencias Económicas.

2 La noción de "bien común" es aristotélica y tomista. La de "bien-estar", acuñada por Amartya Sen, va más allá de esas nociones y profundiza su alcance remitiendo a la autonomía y la libertad individual para que los individuos alcancen estados valiosos de ser y hacer. 
y crisis ambientales-, y las respuestas que la ciencia económica da a esas demandas. Se ha señalado, sobre la ciencia económica, la falta de pertinencia, realismo y coherencia y como problema fundamental un vigoroso academicismo estéril. Amartya Sen dijo en el prefacio de su libro sobre crecimiento económico, que los numerosos y sofisticados modelos formales del crecimiento económico, al parecer, han influenciado poco o nada las acciones prácticas de las sociedades: "Su conexión con la política pública ha sido a menudo muy remota” (Sen, 1979, p. 7).

La afirmación de Sen expresa el malestar acerca del desencuentro entre las ciencias económicas y las realidades que viven sociedades e individuos, y llevan al cuestionamiento de la denominada "corriente principal" de las ciencias económicas. Si se entiende, la pertinencia como la correspondencia entre los problemas económicos de la sociedad contemporánea y las soluciones que brinda la ciencia económica; el realismo como la percepción y la manera de dar cuenta la economía de los fenómenos tal y como suceden; y la coherencia como la forma en que las distintas áreas de la economía contribuyen a la solución de los problemas, es posible agregar a esta percepción de desencuentros una idea más, referida a los principios de la teoría económica.

Ronald Coase, en su importante artículo The Nature of the Firm (1937), señala que una de las fallas que ha presentado la teoría económica ha sido la

... de no establecer claramente sus principios. Los economistas, al construir una teoría, frecuentemente han omitido examinar las bases en las que esta descansa. Este examen es, no obstante, esencial no solo para prevenir el malentendido y la innecesaria controversia que surge por una falta de conocimiento de los principios en los que se basa una teoría, sino también por la extrema importancia que para la economía tiene el buen juicio de escoger entre series de principios rivales (p. 558).

Coase amplía estas ideas citando a Joan Robinson (1932, p. 12): “las dos preguntas que se deben hacer sobre una serie de principios en la 
economía son: ¿`son manejables?, y ¿corresponden al mundo real? (...) será más frecuente encontrar que una serie de principios es manejable y la otra realista”. Y agrega: “... bien puede haber ramas de la teoría en la que los principios sean tanto manejables como realistas" (p. 558).

Las apreciaciones de los autores mencionados relativizan la forma cómo la economía neoclásica (el programa walrasiano, el consenso macroeconómico expresado en el modelo IS LM, los fundamentos de la racionalidad plena, la maximización de la utilidad...) ha buscado emparentar sus fundamentos con las leyes de la física. La economía neoclásica ha exacerbado la formalización matemática, llevándola a extremos en los que, en palabras de los economistas institucionales, las ciencias económicas parecieran haberse desentendido de las personas, de los seres humanos de carne y hueso. En otros términos, la absolutización del método físico-matemático, considerado como único válido, ha olvidado tomar en cuenta la naturaleza del objeto de conocimiento económico: el ser humano, las organizaciones sociales complejas. Existe hoy en día una discrepancia entre las ciencias económicas y la realidad: las teorías se muestran poco útiles a la hora de buscar su aplicación en la práctica y por tanto incapaces en apariencia de comprender y transformar realidades. La exacerbación por el uso de métodos cuantitativos y por el diseño de modelos, han hecho olvidar a algunos economistas de los problemas económicos reales de la humanidad. La utilización de analogías fundamentalistas con las ciencias naturales, especialmente la física, han llevado a la economía a que desdeñe toda consideración ética. Todas estas herramientas bien utilizadas ayudarían considerablemente a la solución de problemas económicos de la humanidad, siempre y cuando, el economista no olvide la fundamentación teórica y, más importante aún, el marco ético que permita lograr la justicia social.

Una de las manifestaciones derivadas del desencuentro entre las ciencias económicas y los problemas reales de las sociedades y los individuos, fue la discusión que se adelantó durante la segunda mitad del siglo xx en torno a las nociones de crecimiento y desarrollo. Cada uno de esos términos fue objeto de controversias a la luz de los resultados observados en el progreso económico de los países y el bienestar de 
sus habitantes. El cuestionamiento de si el crecimiento es el principal objetivo de la sociedad es de vieja data. En los países desarrollados se ha puesto en tela de juicio esta obsesión con argumentos fundamentados en la evidencia de un crecimiento industrial acompañado del agotamiento de los recursos naturales y la contaminación del medio ambiente. En los países en desarrollo, el crecimiento se ha desenvuelto pari passu $u^{3}$ con una elevada concentración del ingreso y un empobrecimiento cada vez mayor de la población.

Durante los años cincuenta a setenta del siglo pasado no hubo una distinción plena entre crecimiento y desarrollo; este último se asociaba al nivel de incremento anual del producto interno bruto y al ingreso nacional per cápita por encima de las tasas de crecimiento de la población. Desde la teoría del cambio estructural, el desarrollo se entendió como el resultado de la planificación orientada a una mayor participación de la industria y los servicios, en contraste con otros sectores de la actividad económica, y al mejoramiento de indicadores no económicos, entre otros la alfabetización, la escolarización, los servicios sanitarios y los programas de vivienda. "El desarrollo se consideró como un fenómeno económico, por el cual el crecimiento del PIB y del PIB per cápita repercutiría poco a poco en toda la población en forma de empleo y otras oportunidades económicas o crearía las condiciones necesarias para una distribución más amplia de los beneficios económicos y sociales del crecimiento" (Todaro, 1985, p. 118). Pero muy pronto surgió la necesidad de una reflexión más profunda sobre los temas del desarrollo, al incluir las interrogantes sobre los problemas de la pobreza, el desempleo y la desigualdad. Ante la presencia y la persistencia de estos problemas, aún en situaciones de crecimiento del ingreso por habitante, ya no era posible seguir asimilando el desarrollo como crecimiento.

De ese modo, el concepto de desarrollo implicó la búsqueda de un crecimiento con equidad. En los países más industrializados surgió una

3 Pari passu es una frase en latín que literalmente significa "con igual paso", lo que suele traducirse como "en igualdad de condiciones", "al mismo nivel". 
creciente preocupación por el uso irracional de los recursos naturales y la contaminación. No obstante este cambio de visión, la recesión de la economía internacional en los años ochenta, la deuda externa y los problemas inflacionarios, llevaron a que los objetivos económicos centrales fueran la estabilidad macroeconómica y la recuperación del crecimiento económico. Las décadas de los ochenta y los noventa fueron tiempos destinados a los programas de estabilización y ajuste económico. Estos procesos agravaron los problemas de la pobreza, la desigualdad, la exclusión social y el deterioro ambiental, prácticamente en todos los países en vías de desarrollo.

Sin embargo, de manera simultánea, se venía consolidando un nuevo concepto de desarrollo: el desarrollo humano sostenible, una noción que armoniza las ideas de crecimiento con equidad y sostenibilidad social y ambiental. Estos conceptos se inspiraron en la Declaración de los Derechos Humanos (ONU, 1948), que propugnó por el respeto de los derechos fundamentales de la persona humana, incluidos los derechos a la subsistencia, a la autoestima y a las libertades. Otros conceptos se desarrollarían a la luz de los principios de la teoría de la justicia de Rawls $(1971)^{4}$ o en una visión de la filosofía aristotélica del bien común -esta última implícita en la filosofía tomista, el pensamiento de Lebret expresado en economía y humanismo y la formulación del desarrollo bajo la noción de capacidades, propuesta por Amartya Sen-, en la que concibe el desarrollo como el bien-estar de las personas, la posibilidad de ser y hacer a partir del ejercicio de las libertades y de los derechos, el desarrollo de las capacidades de las personas, las realizaciones plenas de un estilo de vida y el disfrute de las oportunidades que una sociedad puede ofrecer a sus ciudadanos según el nivel de desarrollo económico y social alcanzado.

4 En Teoría de la Justicia, John Rawls, expone de manera implícita estas nociones de justicia distributiva y amplia las nociones sobre el rol del Estado y de los gobiernos democráticos en torno al papel de la justicia. En particular conviene subrayar los dos principios que Rawls propone en su teoría: (i) cada ser humano tiene derecho al más amplio y completo conjunto de libertades iguales para todos; (ii) las desigualdades son aceptables en la medida en que sea razonable esperar que conduzcan al beneficio de todos. Las ideas de Rawls sobre la justicia son sustantivas en las discusiones alrededor de la economía. 


\section{El enfoque de las capacidades -ser y hacer- como noción de desarrollo}

Las desigualdades de ingresos y de riqueza y las situaciones de pobreza extrema fueron fuente de indagaciones que desbordaron las preocupaciones propias del crecimiento económico e introdujeron los desarrollos teóricos del desarrollo a largo plazo desde un punto de vista aplicado (Sala-i-Martin, 1994, p. 5). Los enfoques del desarrollo han sido, como en el crecimiento, igualmente diversos, aunque su punto de partida fueron las preocupaciones comunes: i) los problemas de pobreza rural y las migraciones del campo a la ciudad, que remiten a soluciones de uso de la fuerza de trabajo desocupada y a la aceleración en la acumulación de capital y, ii) procesos de industrialización tardía, que motivaron una activa intervención del Estado y un ejercicio deliberado de planeación (Hirschman, 1981, p. 10-11).

En la corriente principal de la economía, la industrialización, la rápida acumulación de capital, la utilización de la fuerza de trabajo desocupada, la planeación y la intervención activa del Estado en la economía aparecen, en ese orden de prioridad, como los objetivos de las políticas del desarrollo (Sen, 1985, p. 940). El reconocimiento de sus logros y fracasos se ha estimado en la magnitud del producto nacional, el ingreso per cápita y la oferta total de bienes, es decir, en las ideas mismas del crecimiento económico.

El éxito de las economías de mercado en los países del este asiático y el estancamiento del crecimiento económico en América Latina y África llevaron a distintas valoraciones, críticas e interpretaciones de los enfoques del desarrollo, v. gr. la mayor o menor intervención del Estado en la actividad económica, la mala asignación de recursos en los procesos de industrialización y los equívocos en los diagnósticos sobre necesidades de acumulación de capital versus prácticas organizativas y de gestión de las empresas. Los hechos históricos han proporcionado razones encontradas en cada uno de estos temas. El de la planificación centralizada y la activa gestión gubernamental en el mercado ha sido ampliamente discutido: mientras en algunos países (China, Sri Lanka, Costa Rica, Corea del Sur) la activa participación del Estado derivó en índices de crecimiento elevado y progresos significativos de 
los indicadores sociales, en otros (Pakistán, y gran parte de los países de África y América Latina durante las décadas de los setenta y ochenta) la intervención estatal demostró ser un serio obstáculo para el crecimiento y el desarrollo.

En general, parte del fracaso de esas premisas del desarrollo se explican por los elevados y constantes niveles de pobreza, desempleo y crecientes desigualdades en la distribución de la renta. En la mayoría de los países en desarrollo que registraron cambios importantes en la acumulación de capital y en industrialización y aumentaron los niveles de ingreso per cápita en un contexto de comparaciones internacionales, los problemas de pobreza y desigualdad permanecieron prácticamente inalterados. Altos ingresos per cápita y alta concentración del ingreso y la riqueza no resuelven los problemas señalados atrás.

En opinión de Sen, las limitaciones reales a la economía tradicional del desarrollo no provinieron de los medios escogidos para alcanzar el crecimiento económico, sino de un reconocimiento insuficiente de que dicho proceso no es más que un medio para lograr otros fines. Sen (1981, 1982a, 1982b, 1983c, 1985) propone un enfoque distinto al de la corriente principal, que va más allá del concepto de desarrollo tradicional basado en el crecimiento (producto nacional, ingreso agregado, oferta total de bienes), sin desconocer que este es justamente un medio para los objetivos del desarrollo: el enfoque de los "derechos" de la gente y las "capacidades" que generarán esos derechos. "En última instancia, el proceso de desarrollo económico debe preocuparse de lo que la gente puede o no hacer, es decir, si pueden vivir más, escapar de la morbilidad evitable, estar bien alimentados, ser capaces de leer, escribir, comunicarse”. Y complementa: “(...) se trata de sustituir el dominio de las circunstancias y el azar sobre los individuos por el dominio de los individuos sobre el azar y las circunstancias".

Sen define los derechos como el conjunto de grupos de bienes optativos a los que una persona tiene acceso en una sociedad cuando utiliza la totalidad de opciones y oportunidades que tiene frente a sí. El acceso a los derechos permite a las personas el desarrollo de sus capacidades. El proceso de desarrollo económico puede verse como el proceso de aumentar las capacidades de la gente. El enfoque se centra 
en lo que la gente puede hacer y el desarrollo se ve como la emancipación de la obligación de necesidad de "vivir menos o ser menos" (Sen, 1983, p. 1115).

Dada la relación funcional entre los derechos de las personas sobre los bienes y sus capacidades, una caracterización útil, aunque derivada, del desarrollo económico, consiste en equipararlo a la expansión de los derechos (Sen, 1985, p. 945). El enfoque de las capacidades se relaciona con aquellas caracterizaciones que conciben el desarrollo como: 1) la expansión de bienes y servicios, 2) el aumento de la utilidad y, 3) la satisfacción de las necesidades básicas.

La calidad de vida puede evaluarse en términos de "la capacidad para lograr realizaciones valiosas” (Sen, 1993, p. 1). De las dotaciones iniciales, el desarrollo de las capacidades y el ejercicio de los derechos devienen en un determinado nivel de calidad de vida. En el tema de la vivienda, un ambiente adecuado y seguro contribuye de manera significativa al desarrollo de las capacidades de las personas: satisfacción de necesidades del ser humano relacionadas con la subsistencia (salud física y mental), protección, afecto (autoestima, solidaridad), participación, ocio, creación, identidad (autonomía, pertenencia) y libertad.

La conversión de los bienes en capacidades depende de factores sociales que el individuo no controla. La persona que ha realizado un gran esfuerzo con el fin de mejorar su nivel educativo, puede que no encuentre trabajo en el mercado laboral. Esta falta de oportunidades le impide obtener unos ingresos salariales a cambio de sus dotaciones educativas. Se presenta, entonces, una ruptura entre "el vector de dotaciones y el mapa de los derechos de intercambio" (Sen 1983b, p. 1118).

Los derechos son la base a partir de la cual puede evaluarse el desarrollo de las capacidades. Estas van más allá de las nociones de habilidad y productividad, propias de la teoría del capital humano (Sen, 1997b), que considera a la persona un recurso productivo: vale solo si produce. En contraste, el concepto de capacidades se relaciona directamente con la libertad de las personas. Las capacidades aumentan con las titularidades. La puesta en acción de las capacidades crea las condiciones para el ejercicio efectivo de los derechos. 
La pobreza significa carencia de capacidades y derechos. Si el Estado y la sociedad no establecen en forma adecuada las condiciones mínimas en dotaciones iniciales para todas las personas, estas no podrán hacer efectivo el ejercicio de los derechos y tampoco podrán desarrollar sus capacidades. Derechos y capacidades van de la mano con la obtención de realizaciones valiosas para la vida de las personas: las diferencias de oportunidades podrán considerarse accesibles a todas las personas.

Sen insiste en que no basta atender la limitada concepción del desarrollo basada en el crecimiento con la preocupación de una equitativa distribución del ingreso. El acceso a los derechos como condición de desarrollo de capacidades y realizaciones de las personas, trasciende los límites de la economía y exige un sistema público (presiones políticas y sociales) comprometido en erradicar los problemas de la pobreza, la exclusión y la desigualdad.

\section{Otras consideraciones teóricas}

En los debates recientes entre las diferentes escuelas de pensamiento (keynesiana, neoclásica, monetarista, neokeynesiana, estructuralista y regulacionista, entre otras), hay temas de economía social implícitos o explícitos tan importantes como la redistribución, la equidad y la eficiencia, el análisis contextual y la apertura a otras ciencias sociales. Las siguientes son algunas de las consideraciones plausibles de tener en cuenta:

- La opción del pensamiento clásico por la libertad de los mercados (a partir de la teoría del valor, el crecimiento, y la distribución), nace de que la conciencia de los conflictos sociales requieren grandes transformaciones.

- El pensamiento marxista es una reivindicación del papel central del trabajo en los procesos históricos de la creación del valor.

- Los neoclásicos, en especial a través del modelo de equilibrio general de Walras (1926), evidencian un gran interés teórico con la interrelación de los sectores sociales en una economía eficiente, pero no necesariamente más equitativa. 
- Alfred Marshall (1890), animado por un espíritu humanitario a favor de los grupos sociales de menores ingresos, propugnó por un enfoque unificado de las ciencias sociales.

- Los postulados institucionalistas a favor de la iniciativa estatal en materia económica, tendrían gran influencia en la política posterior como lo evidencian la política social británica y el New Deal ${ }^{5}$ norteamericano.

- La nueva economía política de la elección pública a partir de la indisputabilidad entre economía y política, llama la atención sobre las fallas del mercado y su incapacidad frente a los requerimientos sociales y asignación óptima.

- Ante los crecientes índices de pobreza de la economía global de hoy, adquieren mayor relevancia los aportes de Kenneth Arrow, Joseph Stiglitz y Amartya Sen, entre otros, para la caracterización e interpretación del fenómeno de la pobreza, la función de bienestar social y la formulación de políticas económicas con beneficio social.

Un aspecto importante dentro de esa descripción lo constituye el progresivo desarrollo de la expresión matemática de la economía, que ha permitido una mayor formalización y rigurosidad en la formulación de los diferentes conceptos de la ciencia económica. Este proceso arranca con la teoría neoclásica y está todavía en proceso de consolidación.

Así mismo, se reconoce que la ciencia económica se enfrenta a un proceso muy particular del capitalismo, definido como globalización, producido por los nuevos problemas de la sociedad, lo cual plantea retos de observar a la luz de estos nuevos fenómenos los alcances de la disciplina y el replanteamiento de algunas teorías.

5 El New Deal (o "nuevo trato" en español) fue un conjunto de medidas económicas puestas en marcha por el presidente norteamericano Franklin D. Roosevelt entre 1933 y 1937, para actuar de forma enérgica sobre lo que se consideraban las causas de la grave crisis económica de 1929. Esta nueva política económica se fundamentaba en el intervencionismo estatal y en la firme creencia en las teorías del subconsumo. 


\section{Líneas activas y programas de investigación en la Facultad de Economía}

La Facultad de Economía ha venido consolidando los procesos de investigación en cuatro líneas que corresponden a las enfoques de economía pública y social, economía financiera, economía de las organizaciones y economía de la salud.

\section{Línea Economía Pública y Social}

\section{Economía pública}

Durante el siglo xx, las investigaciones y los desarrollos teóricos en el ámbito de la economía pública tuvieron un desarrollo notable. La preocupación por el papel del Estado en el desarrollo de los países ha derivado en corrientes de pensamiento que, en una perspectiva muy general y en el contexto de sociedades democráticas y economías de mercado, muestra escenarios sobre los cuales se definen las funciones del Estado y su relación con el mercado, desde las posturas teóricas que abogan por Estados intervencionistas para controlar las crisis previsibles en los ciclos económicos y garantizar el bienestar general (Keynes y los autores denominados poskeynesianos), hasta los aportes que promueven un protagonismo mayor del mercado -discusión entre nacionalización y privatización-, y un rol discrecional del Estado en el campo de la regulación, las acciones subsidiarias y la compensación en situaciones de fallas de mercado (Friedman y los seguidores del monetarismo neoclásico - escuela de Chicago).

La corriente de pensamiento económico keynesiano y poskeynesiano consolida la perspectiva de los Estados benefactores, cuyo auge pudo observarse en las economías occidentales especialmente durante las décadas de los cincuenta a los ochenta del siglo pasado. En cambio, las posturas teóricas basadas en los paradigmas de la escuela de Chicago, dieron sustento a las transformaciones de los modelos de desarrollo en el mundo occidental desde finales de los noventa, en las que se desmontaron en gran medida las estructuras del Estado benefactor 
y se instauran instancias institucionales que dan lugar a un papel estatal más proclive a la regulación.

En medio de los dos escenarios teóricos que ponen en el centro de las discusiones el papel del Estado y su relación con el mercado, surgieron a la largo del siglo xx otras manifestaciones teóricas en las que se ponen de relieve: la condición de los individuos, los colectivos sociales y las instituciones. Entre otras, son de mencionar la teoría de la elección colectiva, a la que dieron aportes sustantivos autores como Tullock (1959, 1974), Arrow (1963, 1974, 1994), Buchanan (1954, 1962, 1972) y Sen (1976, 1979, 1982a, 1982b, 1983a, 1983b, 1983c, 1985, 1987, 1993, 1995), y las corrientes de pensamiento denominadas economía institucional y neoinstitucional (Veblen (1899, 1904), Simon (1957, 1972, 1979, 1991), Coase (1937, 1988), North (1990), Hodgson (1994, 1998), Williamson $(1975,1985,1993)$ y Ostrom (1990), entre otros, que subrayan, más allá de los supuestos teóricos de la economía neoclásica, que en la realidad económica y social existen otras variables explicativas de importancia para comprender las dinámicas económicas, sociales y políticas, entre las cuales se mencionan los derechos de propiedad, los costos de transacción, las asimetrías de información, la organización económica y el sistema legal.

En una perspectiva amplia, los diferentes enfoques teóricos remiten necesariamente a las indagaciones sobre las relaciones Estado-mercado, mercado-individuo/colectivos sociales y Estado-individuo/ colectivos sociales. Interesa el tema de los equilibrios en ese marco de relaciones, que podría traducirse en cierta forma como el equilibrio entre la eficiencia económica y la conveniencia por el bienestar (Stiglitz, 1977, 1994, 1997, 1998), en el que los esquemas de libertades, las nociones de equidad e igualdad y justicia, el control y la cohesión social..., hacen parte de las discusiones de la economía pública y remiten necesariamente a una discusión más amplia acerca de la democracia. De manera particular, en el espectro de esas relaciones, es de interés establecer como ámbitos de investigación definidos los relacionados con la fiscalidad, la provisión de bienes públicos y la regulación. 
En esos tres ámbitos a su vez son plausibles los temas de investigación relacionados con el gasto público, sus efectos en el crecimiento económico y las relaciones Gobierno/racionalidad económica, los efectos económicos de los sistemas tributarios, la incidencia de los impuestos en el bienestar, el déficit fiscal y la deuda pública (fiscalidad) y temas como los de la eficiencia en casos de nacionalización o privatización y el papel de la regulación cuyos aportes teóricos son relativamente recientes, desde los ejercicios pioneros en el Reino Unido, a partir de los cuales se han desarrollado aportes sustantivos en las formas de regulación en economías de mercado, algunas de ellas relacionadas con la provisión de bienes y servicios de naturaleza pública. Entre otros autores destacados en este campo, se mencionan a Demsetz (1968), Grossman y Hart (1986), Laffont y Tirole (1993), Train (1994) y Guasch y Spiller (1999).

\section{Economía social}

El énfasis de economía y humanismo promueve la investigación sobre las complejidades de la realidad humana en sus aspectos económicos y sociales, con el fin de crear capacidades que permitan determinar las condiciones concretas del bien común y la justicia distributiva, de participar en los esfuerzos públicos o privados y de reorganización económica dirigidos a su consecución. En esta perspectiva se abordan los problemas de la distribución de los recursos en una sociedad. Esa distribución pasa por instituciones sociales y políticas, y no es el mercado la única institución mediante la cual se hace la distribución, como es el supuesto de la economía estándar u ortodoxa.

El mercado es una institución social, en la cual los individuos intercambian bienes y servicios, a través del dinero, y con espíritu de lucro. Pero también existen los intercambios que no buscan el lucro, o que no están mediados por la moneda. Existen instituciones sociales que intervienen en la distribución de los recursos y por mecanismos por fuera del mercado como es el caso de la familia y la comunidad. Entre tales mecanismos se tienen la reciprocidad y la redistribución (Polanyi) (por ejemplo el cuidado de los hijos por parte de sus padres), el don y el contradón, y la solidaridad. 
En cuanto a las instituciones políticas, la distribución de recursos pasa por la fiscalidad: el cobro de las cargas fiscales (entre ellas los tributos), el endeudamiento público y la asignación del gasto público. Todo esto cae en el ámbito de la noción de economía y humanismo, que incluye una perspectiva histórica del análisis, el análisis del contexto de los fenómenos sociales y el enfoque multidisciplinar.

La distribución implica procesos sociales y políticos, y tales procesos pasan por negociaciones de grupos sociales, los cuales deben invocar discursos ideológicos, prácticas (que incluso pueden ser violentas) y mediaciones institucionales cuyo estudio no solo hacen parte de la economía desde una perspectiva humanista, sino de las demás disciplinas sociales, en particular la sociología, la antropología y la política. La existencia de un orden económico determinado (que a su vez supone un orden social y político) pasa por compromisos sociales frente a los cuales se construyen y se de-construyen ciertas prácticas de pensamiento y de acción.

En la actualidad, el discurso dominante es el de la mercantilización de las relaciones sociales, el riesgo social manejado por los mercados financieros y la gratuidad de unos mínimos sociales solo para los excluidos del mercado (los pobres).

La perspectiva de la economía social trasciende la discusión de la asignación de recursos a través del mercado. La economía estándar, ortodoxa, solo estudia las formas mercantiles y acusa a las formas no mercantiles como fallos de mercado o distorsiones. La economía en perspectiva humanista va más allá y su análisis se extiende a campos tales como: política social, finanzas públicas, el desarrollo en sus diferentes expresiones (económico, social, sostenible, urbano, regional), moneda y banca, organización agraria y economía popular.

Se trata de un campo de estudio complejo y rico, que no alcanza a ser abarcado por el reduccionismo unidisciplinar y mercantil de la economía estándar. Esto significa que la economía en perspectiva humanista no puede ser vista como una disciplina pura sino que al mismo tiempo es histórica, filosófica, política, antropológica, geográfica y social.

Una de las aristas que permiten ver la economía desde la perspectiva humanista, y que se ha propuesto como una forma alternativa 
de ver las realidades económicas, es la denominada socioeconomía, la cual se describe como un campo de investigación que tiene como objeto estudiar los fenómenos económicos en términos de relaciones sociales. Tiene dos implicaciones fundamentales: 1) la clásica división en ciencias humanas y sociales entre disciplinas atomizadas cada una con un objeto de estudio bien definido (todo fenómeno económico en su explicación movilizando siempre varias dimensiones) y, 2) la necesidad de un análisis en términos dialecticos en tanto que las relaciones sociales tienen como característica fundamental el hecho de ser contradictorias, ambivalentes y sujetas a múltiples tensiones.

En estos dos sentidos, la socioeconomía está vinculada a una larga y distinguida tradición teórica que incluye, entre otros, los siguientes trabajos clásicos: La teoría de los sentimientos morales de Adam Smith, La ética protestante y el espíritu del capitalismo de Max Weber, La división del trabajo social de Emile Durkheim, La filosofía del dinero de Georg Simmel, Teoría de la clase ociosa de Thorstein Veblen, El ensayo sobre el don de Marcel Mauss, La gran transformación de Karl Polanyi, y en fin, la obra entera de grandes autores de las ciencias sociales como Karl Marx, Joseph Schumpeter, Albert Hirschman y Celso Furtado, entre otros.

Puede considerarse la socioeconomía como una perspectiva intersticial en ciencias humanas y sociales, una perspectiva puente. Sus categorías de análisis y sus métodos provienen de las diversas ciencias sociales como la historia, la filosofía, la sociología, la antropología y la economía. Por lo demás, una de las principales tareas de los estudios socioeconómicos es precisamente comprender los vínculos y las tensiones existentes entre las diversas lógicas que determinan las decisiones, estrategias, e intereses de agentes y organizaciones que interactúan en un marco institucional concreto y cómo dicho encuentro determina la dinámica del conjunto.

\section{Línea Economía Financiera}

Refiriéndose al costo de capital, Modigliani y Miller (1958) plantean que es un tema que ha inquietado por lo menos a tres grupos de economistas. Primero, a los especializados en finanzas corporativas cuando 
estudian las técnicas de financiamiento de las firmas que les permita asegurar su supervivencia y crecimiento; segundo, a los economistas gerenciales cuando se refieren al tema del presupuesto de capital; y tercero, a los economistas teóricos cuando quieren explicar el comportamiento de los inversionistas tanto a nivel micro como a nivel macro.

Si se aplica este razonamiento lógico al estudio de la economía financiera, entendida como aquella rama de la economía que estudia el comportamiento de los individuos en la asignación intertemporal de sus recursos en condiciones de incertidumbre, así como el papel de las organizaciones económicas y los mercados que facilitan dichas asignaciones (Marín y Rubio, 2001), se puede decir que en la línea de economía financiera, el propósito es investigar el comportamiento de los inversionistas, en los niveles micro y macro, en torno a la asignación intertemporal de recursos en condiciones de incertidumbre, $\mathrm{y}$ el papel de los mercados y de las instituciones que facilitan y regulan ese intercambio, analizando siempre su impacto en el desarrollo social e incorporando el importante papel que juega en todo ello el manejo de la política monetaria.

Los temas objeto de la línea en economía financiera pueden agruparse en cuatro grupos: el primer grupo de temas, busca hacer explícito el propósito de estudiar las condiciones y supuestos de la economía financiera: condiciones de no arbitraje, mercados completos, condiciones de equilibrio, condiciones de incertidumbre, eficiencia de los mercados, entre otros temas. Son de importancia los trabajos de Hirshleifer y Riley (1979) sobre la información; los de Jaffe (1974), Finnerty (1976), Grossman y Stiglitz (1976) y Grosman (1976), sobre las asimetrías de información; los de Grossman y Stiglitz (1976, 1980) y Cornell y Roll (1981), sobre el costo de la información; y los aportes de Ball y Brown (1968), Joy, Litzenberger y McEnally (1977) y Watts (1978), sobre la influencia de la información contable en el comportamiento de los mercados.

Otros trabajos de referencia que se incluyen en este primer grupo temático son los de Fama y Blume (1966), Alexander (1961) y Fama (1970), sobre teoría del juego justo y la forma débil de eficiencia del mercado; Kraus y Stoll (1972), Dann, Mayers y Raab (1977), hacen 
aportes relevantes al tema de las negociaciones en bloque en los mercados de valores; los trabajos de Frank Knight (1921), sobre la economía del riesgo y la incertidumbre, en los que la organización es tenida en cuenta como unidad socioeconómica, son pertinentes.

El segundo grupo de temas de estudio, se refiere a las decisiones de los inversionistas -individuos e instituciones financieras- que eligen valores para la conformación de sus portafolios de inversión. La teoría del portafolio de Harry Markovitz (1952), basada en la teoría de elección y complementada por el teorema de la separación de J. Tobin (1958), ha constituido uno de los pilares teóricos de las finanzas en el tema de inversión que, sumados a investigaciones como la de Wagner y Lau (1971) sobre los efectos de la diversificación, han sido recogidos por el modelo de valoración de activos de capital (CAPM) desarrollado originalmente por Sharpe, Trynor, Mossin y Litner y que finalmente les otorgó el Premio Nobel de Economía en 1990 a los profesores Markovitz y Sharpe.

Dentro de este segundo grupo se incluye el tema de la administración financiera, también llamada finanzas en las organizaciones, en el que se destacan trabajos sobre apalancamiento (Rubinstein,1973); betas apalancadas y estructura óptima de capital (Modigliani y Miller, 1958), retomado posteriormente desde una perspectiva institucionalista por Oliver Williamson (1988); costo de capital con impuestos corporativos y personales (Miller, 1977); efecto de las protecciones fiscales múltiples (De Angelo y Masulis, 1980); implicaciones de la fijación de precios de las opciones para la estructura de capital (Black y Scholes, 1973 y Merton, 1973); problemas de la agencia en la estructura de capital (Jensen y Meckling, 1976); asimetrías de información y señalamiento (Ross, 1977 y Leland y Pyle, 1977); y las investigaciones sobre políticas de dividendos (Miller y Modigliani, 1961; Gordon y Litner, 1963; Farrar y Selwyn, 1967; Brennan, 1970; y Black y Sholes, 1974).

El tercer grupo de temas se refiere a la teoría y política monetaria, considerada uno de los principales medios de intervención económica por parte del Estado a través de las tasas de interés, la tasa de cambio, la inflación y la demanda agregada. El fin principal de la política monetaria es mantener la inflación baja y estable sin que sean indiferentes 
los temas de crecimiento económico y desempleo. Se argumenta que la manera de contribuir al crecimiento de una economía es aportando estabilidad de precios: una inflación más alta está asociada a un menor crecimiento económico. La política monetaria es una herramienta poderosa, pero sus consecuencias pueden ser a la vez indeseables, en tanto puede afectar a la economía en su conjunto.

Otro tema importante es la transmisión regional de la política monetaria, ya que esta puede causar efectos regionales, en razón a que las regiones no son iguales en sus estructuras económicas, por ejemplo, en el grado de industrialización, desarrollo del sistema financiero, comercio exterior, niveles de desempleo o niveles de pobreza. En la política monetaria se encuentran algunas de las razones que explican por qué la política monetaria puede tener efectos diferentes en las distintas regiones de Estados Unidos. Para cuantificar la diferencia regional en el efecto de la política monetaria, estos autores usan un modelo de vectores autorregresivos y análisis de impulso-respuesta para las ocho regiones norteamericanas entre 1954 y 1992. Las variables que incluyen son la tasa de crecimiento del ingreso personal, el precio relativo de la energía y las variables de política monetaria. Las diferencias regionales también se pueden analizar a la luz de los efectos de la política monetaria.

Un tema de interés en este primer grupo se refiere al papel que juega el sistema financiero en el desarrollo económico. Aunque se han planteado cuestionamientos a esta relación ${ }^{6}$, existe consenso sobre el hecho de que países con alto desarrollo financiero tienden a mostrar un mejor desempeño económico mediante la canalización del ahorro hacia la inversión con bajos costos de transacción, transformación de plazos, manejo de riesgos, aumento de la productividad del capital, financiación de nuevos proyectos innovadores y apoyo al crecimiento

6 Lucas (1988) plantea que se ha sobredimensionado la relación entre sistema financiero y crecimiento; Robinson (1952) dice que los desarrollos en el sector real son causa del desarrollo financiero y no al contrario; y otros autores plantean que el desarrollo del sistema financiero incide negativamente en la tasa de ahorro y por lo tanto, en el crecimiento económico. 
de las empresas (Levine, 1998). Se han realizado trabajos empíricos que demuestran que el mercado intermediado contribuye al crecimiento económico ${ }^{7}$, que mercados de capitales líquidos y dinámicos estimulan el crecimiento ${ }^{8}$, y que la complementariedad de los dos es necesaria para lograr el mismo objetivo?

En este mismo orden de ideas es importante revisar el papel de las microfinanzas durante las últimas décadas, entendidas como la provisión de servicios financieros a personas en condiciones de vulnerabilidad, tema que ha cobrado especial relevancia como vehículo de desarrollo económico y en aspectos socioeconómicos tan importantes como la bancarización de la población pobre a través de acceso a cuentas de ahorro y a préstamos pequeños, asesoría para el desarrollo de negocios familiares, sostenibilidad de bancos especializados en microfinanzas y costos para los pobres cuando el servicio de microfinanzas lo provee una entidad bancaria tradicional, entre otros.

El cuarto grupo de temas se refiere a la arquitectura económica internacional. Las recientes crisis económicas originadas en gran parte por las crisis financieras han suscitado álgidos debates que han avivado el interés por la estructura y funcionamiento de la arquitectura institucional de la economía mundial, específicamente por el papel de las instituciones, las estructuras y las políticas actuales.

7 Ver trabajos de Beck, Levine y Loaiza (2000), Levine (1998, 1999), King y Levine (1993) y Stiglitz (1995).

8 Ver Levine y Zervos (1996, 1998), Levine (1991), sobre mejor manejo de riesgo y Rajan (1992) sobre la necesidad de más fomento a la innovación.

9 Pueden consultarse los trabajos de Beck, Demirguc-Kunt, Levine (2003), Beck y Levine (2002), Levine (2002), Rousseau and Wachtel (2000), los que concluyen que bancos y mercados se complementan y promueven desarrollo económico; Rajan y Zingales (1998), Beck y Levine (2004) que demuestran que firmas altamente dependientes del financiamiento externo crecen más rápido en países con sistemas financieros más desarrollados; Demirguc-Kunt y Maksimovic (2000) que plantean que en términos generales las firmas crecen más rápido en sistemas financieros desarrollados y (2000) en el que demuestran que las firmas que requieren de financiamiento a largo plazo se benefician de mercados más dinámicos y desarrollados, y Beck y Levine (2004) que plantean que el desarrollo financiero explica el crecimiento industrial en número de firmas pero no en tamaño. 
Muchos analistas consideran como un objetivo la necesidad de garantizar la estabilidad financiera internacional que lleve a los países a un mejor desempeño económico, que permita avanzar en la reducción de la pobreza y el mejoramiento de las condiciones de vida de los habitantes del planeta. La estabilidad financiera y la reducción de la pobreza son objetivos interdependientes. La primera tiene sentido si contribuye al mejoramiento de la calidad de vida y la calidad de vida es condición necesaria para que el sistema sea estable.

Se plantea entonces la necesidad de revisar las funciones de las instituciones financieras multilaterales ya que el entorno dentro del que fueron creadas ha cambiado tanto como sus objetivos. El objetivo de la creación del Fondo Monetario Internacional (balanza de pagos, patrón oro, tipos de cambio), hoy en día no es pertinente, y el del Banco Mundial (financiación de los países pobres) tendría unas premisas erradas en el marco de una economía globalizada.

Los cuatro grupos temáticos propuestos en el énfasis de economía financiera, tienen validez dentro del Proyecto Educativo Institucional (PEI) y responden a demandas de nuestra sociedad. Con ellos se busca aportar a soluciones de problemas reales y contribuir al mejoramiento de la calidad de vida de la sociedad.

\section{Línea Economía de las Organizaciones}

La organización puede entenderse en dos dimensiones: como ente y como actividad. Como ente, es un sistema abierto que dentro de un marco de regulación, utiliza los recursos a su disposición de manera ordenada y coordinada para obtener unos fines preestablecidos. Como actividad, es el acto de utilizar de manera coordinada todos los recursos disponibles para alcanzar unas metas definidas con anterioridad.

El estudio de las organizaciones se ha realizado desde dos ópticas diferentes: 1) desde el interior de la misma, estudiándola como lugar de decisiones y de relaciones entre los participantes sobre fenómenos de autoridad, jerarquía y control, problemas de información interna y comunicación entre sus miembros, y motivación dentro del marco organizacional y, 2) atendiendo a su relación con el entorno. Existen dos maneras de estudiarla: la primera, corresponde a un enfoque 
constructivista, concentra su análisis sobre los mecanismos internos de las organizaciones elementales, con el ánimo de arrojar conclusiones sobre las relaciones entre organizaciones y por tanto del funcionamiento del sistema económico, social y ambiental. La segunda, toma como punto de partida las características del sistema económico y social para descender al estudio de la organización. En otras palabras, como lo sugirió Arrow (1974), se parte de una visión global de organización, la cual caracteriza la disposición de los componentes de un sistema económico.

La administración se ocupa de la primera perspectiva, el estudio intraorganizacional, y en algunas de sus líneas de trabajo, del primer enfoque dentro de la segunda perspectiva, el constructivista. La economía, en algunas de sus áreas de conocimiento (economía de las organizaciones, economía institucional, microeconomía, teoría de la organización industrial), se ocupa de la segunda perspectiva, especialmente del segundo enfoque.

En la línea de economía de las organizaciones, el propósito es estudiar la segunda perspectiva dentro del segundo enfoque, esto es, partir del análisis de las características del sistema económico para descender al estudio de la organización, atendiendo siempre al impacto que estas generan en la sociedad y, especialmente, en la calidad de vida de las personas.

Para el desarrollo de esta línea, se cuenta con una muy buena literatura, en la que sobresalen trabajos de connotados autores, lo que permite evidenciar la rigurosidad de los posibles trabajos de investigación. Específicamente, la teoría económica, a través de algunos de sus más destacados representantes, ha encontrado un sitio importante para la organización en sus propuestas. Marshall (1890), después de definir la economía, precisar algunas nociones fundamentales y estudiar las necesidades y su satisfacción, introduce el concepto de organización en el Libro IV titulado "Los agentes de la producción: tierra, trabajo, capital y organización”. En el capítulo vin comienza el estudio de la organización industrial, introduciendo la división del trabajo y la influencia de la máquina en el Ix, estudiando la concentración de las industrias especializadas en las localidades particulares en el capítulo $\mathrm{x}$, la 
producción en gran escala en el XI, y culminando con el análisis de la dirección de los negocios en el capítulo XII.

Siguiendo a Ménard (1990), se puede argumentar que Marshall introduce tres categorías de organización en el centro de su dispositivo teórico. En el capítulo IX define la organización como un principio, que por analogía con la biología, asegura la unidad de las organizaciones económicas complejas. En un segundo nivel, señala a la organización como un sistema social en el cual la actividad económica se ha vuelto autónoma. En el tercer nivel la organización económica señala la unidad de decisión elemental, esencialmente las firmas.

Knight (1921), en su estudio sobre incertidumbre y riesgo, considera que el desconocimiento de los acontecimientos futuros genera incertidumbre. Cuando a esta se le pueden asignar probabilidades de ocurrencia se considera riesgo. El autor pone a la organización empresarial y a sus procesos de producción en el centro de su análisis para señalar que el empresario que participa, a través de su organización, en procesos productivos de bienes o de servicios, por trabajar bajo condiciones de incertidumbre debe obtener un beneficio. Para Knight, la incertidumbre es la justificación de la obtención de un beneficio económico por parte de los empresarios. Después de haber estudiado la incertidumbre y el riesgo, introduce su análisis bajo condiciones de competencia perfecta. En la tercera parte estudia el riesgo y la incertidumbre como causa de las condiciones de competencia imperfecta. Estudia la empresa, investigando en el capítulo Ix las relaciones entre la empresa y el beneficio, y en el capítulo $\mathrm{x}$ al director asalariado.

Arrow (1970), en la misma línea de Marshall, considera a la organización como el principio que caracteriza un conjunto económico y social. El mismo Arrow (1974) estudia la organización como unidad de decisión, su sistema de información y su estructura de comunicación. El trabajo de Arrow supera la consideración tradicional del mercado que incluye al Gobierno como único tipo de organización, para introducir otro tipo de organizaciones en el análisis.

Coase (1937), introduce el término "firma" en el análisis económico, en el sentido de industria y critica el uso tradicional que la considera como un plan individual. La utilización de la "firma" en el sentido 
de industria garantiza a la teoría económica dos características que deben tener los supuestos sobre los que trabaja. Deben ser manejables y deben corresponderse con la realidad. Williamson (1985), analiza la organización económica desde un punto de vista institucional comparativo, donde el principal rasgo es la economización de los costos de transacción; y articula el ambiente institucional, el cual se refiere a cuestiones históricas y a las reglas institucionales del juego (costumbres, leyes y política), y las estructuras de governanza (Williamson y Masten, 1999) tratando a la primera como un conjunto de parámetros que al cambiar causan desplazamientos en los costos comparativos de governanza (Gómez, 2006).

Para la escuela austriaca de economía, la fuerza coordinadora del sistema económico es la función empresarial que crea y transmite información. Su función más importante es la de impulsar la coordinación entre los comportamientos desajustados que se dan en la sociedad. Una vez que el empresario se da cuenta de una oportunidad de ganancia y actúa para aprovecharse de la misma, esta desaparece produciéndose un proceso espontáneo de coordinación, que es el que explica la tendencia que existe hacia el equilibrio en toda economía real de mercado (Huerta de Soto, 2000).

Tanto en los autores representativos del pensamiento administrativo como en algunos de los más importantes economistas, se encuentra una preocupación por el estudio del funcionamiento de las organizaciones y la relación de esta con el entorno. Algunos se especializan y estudian un tipo determinado de organización, la organización industrial o empresa.

Cuando la organización tiene como objetivo la maximización del valor para los inversionistas, mediante la utilización ordenada y organizada de los recursos disponibles, enmarcada en normas legales y sociales que la regulan, se denomina empresa. Esta forma parte de las organizaciones como objeto específico de estudio. De esta manera la línea de economía de las organizaciones da cuenta de la empresa como actor principal del devenir económico y de su impacto en la sociedad y en la calidad de vida de las personas. La empresa no es más que un tipo especial de organización. 


\section{Línea Economía de la Salud}

La línea de Economía de la Salud integra de manera preferente dos componentes: la protección social y la salud pública.

\section{Protección social}

La protección social presenta una pertinencia en dos sentidos: los cambios institucionales y el carácter económico y social en la evolución de los sistemas de protección social.

Frente a los cambios institucionales que se han presentado en Colombia, América Latina y el mundo y a los retos de garantizar la protección social plena a la población, se busca generar espacios de reflexión crítica y construcción de conocimiento alternativo, en la perspectiva de proponer esquemas institucionales sólidos que garanticen equilibrios en la eficiencia económica de los sistemas, la inclusión social y el disfrute de los derechos normativos de acceso a la salud y a la seguridad social.

En Colombia, la introducción del concepto de protección social surge a partir de la Constitución Política de 1991, al integrar la salud y las pensiones dentro de la seguridad social, paso que después fue institucionalizado con la adopción de la Ley 100 de 1993. Con la creación del Ministerio de la Protección Social, se incorporaron también los programas laborales y los de asistencia pública con lo cual se dio origen a lo que hoy se conoce como Sistema de Protección Social (SPS).

El concepto de protección social es nuevo en Colombia a pesar de tener una larga tradición en el mundo. Este concepto reconoce que la protección social tiene un carácter integral que comprende los sistemas de pensiones y regulación laboral ${ }^{10}$, los sistemas de salud -antes en cabeza del Ministerio de Salud-, y la asistencia pública. Esta última estaba huérfana porque no era responsabilidad de un ministerio

10 Este tema estaba antes de la Ley 100 de 1993 en cabeza del Ministerio de Trabajo y Seguridad Social. 
en particular, sino que los diferentes programas estaban adscritos a diferentes instituciones.

El hecho de que antes de la Ley 100 de 1993 los programas estuvieran dispersos en diferentes ministerios e instituciones, indicaba que no se tenía en el país un concepto claro de la protección social, a pesar de que las reformas institucionales de muchos países y la literatura integraban el concepto. En el país se pensaba que la seguridad social hacía referencia solamente a pensiones, que la salud no hacía parte de la seguridad social (estaba en un ministerio aparte), y que la asistencia se reducía a programas puntuales de atención social, que no implicaban compromisos permanentes e institucionales por parte del Estado.

Los organismos financieros internacionales, entre ellos el Banco Mundial (BM) y el Banco Interamericano de Desarrollo (BID), adoptaron el concepto de la protección social y, en esa dirección, promovieron reformas en América Latina. Así, desde hace algunos años, el BID ha venido promoviendo la concepción de "universalismo básico". Dada la influencia que tienen estos organismos en las reformas institucionales de la región, la protección social se ha colocado en el primer orden del debate y al respecto existe una abundante literatura.

Existe consenso sobre cuáles son los componentes de la protección social -seguridad social y asistencia pública- y cuáles sus alcances pensiones, salud, ayudas familiares, programas sociales focalizados en poblaciones problema (pobres, vulnerables, discapacitados, desplazados, desempleados...- y, no obstante, hay discusión acerca de concepciones basadas en protección de las personas frente a los riesgos de la vida, acceso a los derechos sociales, bienes sociales que garantizan la reproducción de la fuerza de trabajo y la mitigación social, entre otros. En general, el tema de la protección social es complejo y, en ese sentido, la línea de investigación de economía de la salud busca enfocar de manera integral esa complejidad.

En cuanto al carácter económico y social en la evolución de los sistemas de protección social, se busca establecer una proximidad a las dinámicas económicas y sociales que ponen sobre la mesa el papel fundamental que juegan en la evolución los sistemas de protección social, las tensiones y transformaciones de la sociedad, y cómo el 
accionar social define y redefine las relaciones del Estado, la población y el mercado respecto a los Sistemas de Protección Social (SPS $)^{11}$. En Colombia y en los países de la región, se han evidenciado profundos cambios demográficos y sociales que afectan los SPS: el envejecimiento de la población, la disminución de la tasa de natalidad y el aumento de la esperanza de vida, crean demandas sobre los sistemas de pensiones y de salud, tensiones sociales, presiones políticas sobre el Estado y el Gobierno y presiones financieras sobre el sistema de protección y seguridad social.

Hay otros cambios sociales, como la vinculación de la mujer a la fuerza de trabajo y el aumento de la tasa de separaciones conyugales, que obligan a los SPS a asumir el cuidado de los niños; la desalarización, junto con el aumento del desempleo y la informalidad, que generan demandas de asistencia pública y de recursos, mientras que la base de cotización de los sistemas de aseguramiento se reduce, generando una tensión financiera en los SPS que en algún momento será insostenible si no se revierten las tendencias observadas.

Los problemas mencionados con respecto a los SPS son el objeto de investigaciones de interés en el marco de la línea de economía de la salud, con la finalidad de contribuir a respuestas y propuestas que permitan la inclusión social sin restricciones y la sostenibilidad de los SPS. Los retos en esta materia obligan a revisar enfoques en el campo de la protección y seguridad social a través de procesos transdisciplinares de integración de saberes.

\section{Salud pública}

Para dar cuenta de la aproximación epistemológica es necesario revisar la aproximación epistémico-ontológica del objeto de estudio de la salud pública. Lo anterior requiere tomar una posición frente a la noción de salud y cómo se estudia.

La noción de salud es comprendida como una definición normativa universal que cuestiona la tradicional postura respecto de la

11 USTA (2010). Documento Maestro de la Maestría en Protección Social. 
salud como una definición técnico-científica centrada en la enfermedad (Canguilhem, 1971). Lo anterior, no significa que la salud sea concebida como antagónica a la enfermedad, por el contrario, la singularidad que la acompaña implica cuestionar la dicotomía sano/enfermo, como positivo/negativo, y proponer que salud es la generación de capacidades individuales y sociales para que las personas puedan desarrollar su potencial como seres humanos. Esto implica concebir la salud como un proceso, con características históricas individuales, dado que se configura en trayectorias de vida relacionadas con la historia social de un territorio.

Franco (2011), se cuestiona sobre la idea de lo inherente a lo humano y a la vida. Respecto a lo primero, nos recuerda que los seres humanos somos por excelencia seres con capacidad reflexiva y relacional. Referente a la vida, nos indica la organicidad de la misma y la dialéctica que esta construye con la muerte. Estas nociones cobran hoy más pertinencia ante el aumento de la longevidad, dado que de forma tradicional la salud pública ha relacionado el fracaso con la mortalidad, la cual es relacionada con la finitud. Esta lamentable relación se materializa en la escasa atención que la salud pública da a la reflexión sobre la muerte. Volviendo a Franco (2011), se puede decir que no hay vida si no hay muerte y ambas forman parte del proceso vital humano.

Estas perspectivas cuestionan la definición que la OMS dio en 1942 sobre salud como el mejor estado de bienestar económico y social de las poblaciones, propuesta como regla universal. Por ejemplo, para los pueblos originarios de América Latina, la noción de salud se relaciona con la concepción del sumak kawsay en quechua o "vida en plenitud". Ahora bien, la formulación de la OMS es la base para considerar la salud como derecho humano según la declaración de la ONU.

La explicación de salud como construcción social, y a la vez la noción de la salud como resultado social, conlleva primero que los significados y prácticas que existen sobre la propia noción son diferentes según las formas sociales donde se constituyen y, segundo, que los resultados en salud se relacionan con las formas sociales donde se producen. Estas ideas han sido propuestas por pensadores clásicos de la salud pública: Louis René Villermé y Rudolf Virchow, por citar 
algunos, indicaron la relación entre pobreza y privación material y peores resultados en salud (Campos et al., 1998). Por lo tanto, una enfermedad es socialmente significativa no solo desde su frecuencia de presentación, sino como patrón de ocurrencia de determinación, por las condiciones sociales prevalentes, lo que explica la frecuencia diferencial de enfermedades entre las poblaciones y entre grupos sociales de una misma población (Krieger 2003).

Lo anterior implica retomar la discusión sobre inequidades sociales y la relación con resultados en salud. Las desigualdades en salud guardan como característica el ser sistemáticas y evitables, y obedecen a procesos injustos e innecesarios, además, pueden ser catalogadas como inequidades sociales en salud. Lo anterior refunda el campo de estudio de las relaciones entre lo económico, lo político y lo cultural y la producción y reproducción social del proceso salud-enfermedad de la población. También se debe mencionar el aporte de diferentes escuelas de pensamiento las cuales convergen en afirmar que existe un gradiente social que se relaciona de manera inversa con resultados en salud (Power, 2006; Krieger, 2003). En este campo de análisis, los aportes de la escuela anglosajona de epidemiología social (Power, 2006), los de Nancy Krieger con el enfoque ecosocial (2003) y los aportes de la medicina social latinoamericana son contundentes. Estos teóricos abren nuevos caminos de explicación de la producción y distribución de la enfermedad en las poblaciones.

En síntesis, se puede decir que si bien el estudio entre desigualdad social y resultados en salud no es nueva, buscar las vías que conllevan a que se generen estos peores resultado en salud es un imperativo, máxime ante las nuevas configuraciones sociales y el nuevo orden social que se instaura y que se acompaña de nuevas formas de estratificación social, y de reformas estructurales de los Estados y particularmente del sistema de salud. Asimismo, los procesos políticos de Colombia y del mundo muestran cómo la violencia, declarada en el año 2002 como un campo de interés en la salud pública (OMS, 2002), el envejecimiento poblacional -específicamente el envejecimiento saludable- y las formas de discriminación de género y étnico-raciales, requieren estudios propios de contexto. En este sentido, la comprensión de categorías analíticas 
como la interseccionalidad en el análisis de género y la comprensión étnico-racial (Krieger, 2003), son elementos fundamentales para lograr miradas comprensivas de la salud de las poblaciones.

El tópico de la salud pública, en la línea de economía de la salud, tiene como propósito la comprensión de las relaciones entre las condiciones histórico-sociales de las poblaciones y los procesos de salud-enfermedad. En esa perspectiva, la mirada transdiciplinar es una necesidad en los procesos de investigación en esta materia.

\section{Consolidación de líneas, programas y grupos de investigación}

El Plan Estratégico de Investigación de la Facultad de Economía 20172027 acoge los lineamientos y estrategias del Plan Integral Multicampus y del Plan General de Desarrollo 2016-2019, los cuales se expresan en la consolidación de líneas y grupos de investigación, la articulación de la investigación con la docencia y la proyección social, el posicionamiento y la visibilidad de la investigación, la calidad e impacto en la producción de la investigación y la gestión de redes y cooperación académica.

La consolidación de líneas y grupos de investigación es condición necesaria y suficiente para el desarrollo de las otras estrategias mencionada y, con base en ese presupuesto, la Facultad de Economía ha venido privilegiando esa estrategia. En efecto, desde el año 2009 se viene adelantando un proceso de consolidación de sus líneas de investigación de manera consistente con los fundamentos institucionales y los propósitos investigativos en torno a problemáticas sensibles de la realidad nacional. En ese proceso, de una dispersión de líneas que existían antes de la fecha mencionada -dispersión que también se reflejaba en numerosos grupos de investigación-, se ha dado tránsito a una definición de líneas más precisas y de abordaje de problemáticas de investigación concretas y, por añadidura, a la consolidación de los grupos de investigación.

La gráfica A2 muestra la situación al año 2017 de líneas y grupos de investigación y los resultados que se esperan para el año 2019 en 
materia de consolidación, mediante los procesos que se han adelantado para definir programas y proyectos de investigación relevantes y pertinentes (gráfica A3). En esa perspectiva se espera en el transcurso del período 2017-2027 posicionar y hacer visible la investigación en un contexto de problemas de orden nacional y generar con sus resultados impactos de calidad verificables en los ámbitos de actuación de las comunidades, las empresas y el Estado.

Situación actual (2017)

\section{Líneas de Investigación}

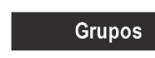

\begin{tabular}{|l|}
\hline 1. Economía Pública \\
\hline 2. Economía Social \\
\hline $\begin{array}{c}\text { 3. Economía de las } \\
\text { Organizaciones }\end{array}$ \\
\hline 4. Economia Financiera \\
\hline
\end{tabular}

\begin{tabular}{ll|}
\hline 5. Salud Pública & $\rightarrow$ Salud Pública \\
\hline 6. Protección Social & $\rightarrow$ Protección Social
\end{tabular}

Situación a 2019

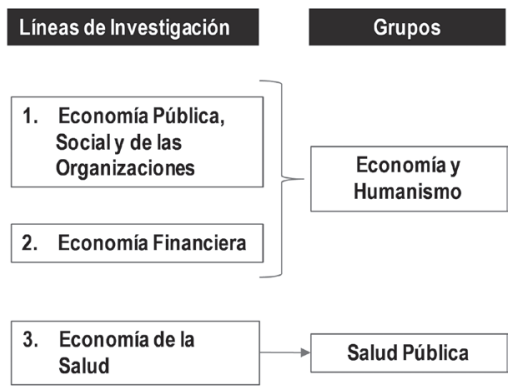

Gráfica A2. Consolidación de líneas y grupos de investigación 2017-2019

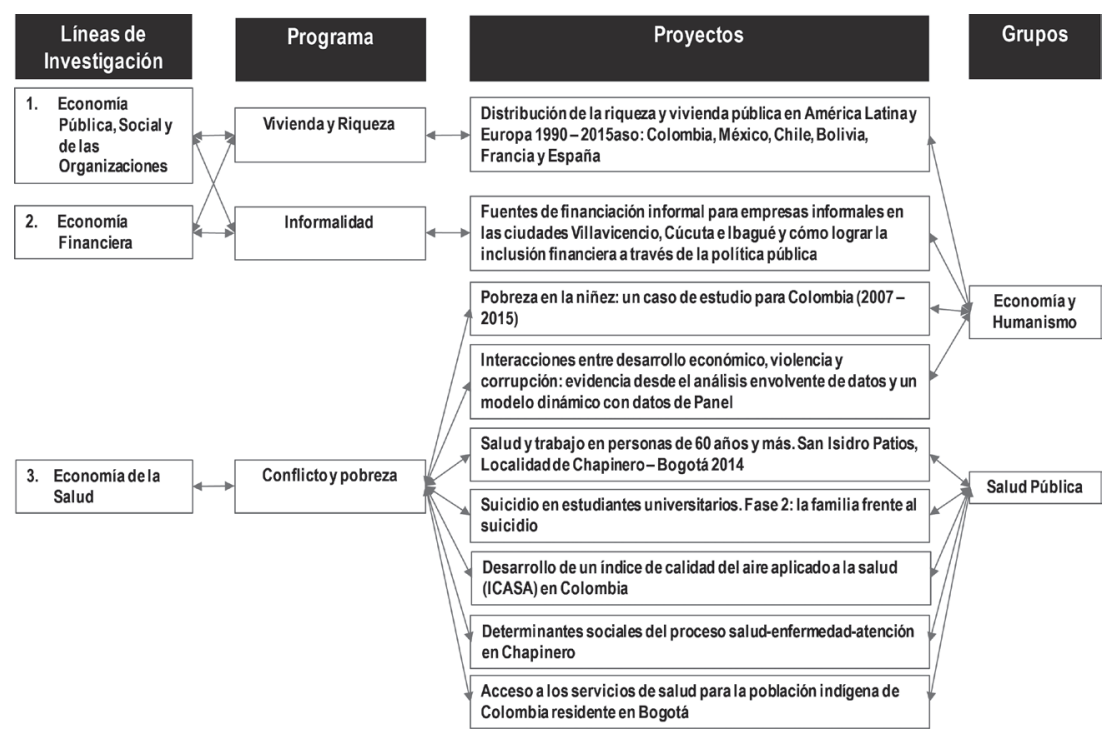

Gráfica A3. Líneas, programas, proyectos y grupos de investigación 2017 


\section{Referencias}

Aharony, J., \& Swary, I. (1980). Quarterly dividend and earnings announcements and stockholders' returns: An empirical analysis. The Journal of Finance, 35(1), 1-12.

Alexander, S. S. (1961). Price movements in speculative markets: Trends or random walks. Industrial Management Review (pre-1986), 2(2), 7.

Arcos, O., Castillo, B., Infante, M., \& Torres, D. (2002). Programa de investigación en economía social. Línea de investigación: Pobreza, Políticas Públicas y Equidad. Universidad Santo Tomás, Facultad de Economía, Maestría en Ciencias Económicas. Bogotá D. C., Colombia.

Arrow, K. J. (1963). Uncertainty and the welfare economics of medical care. American economic review, 53(5), 941-973.

Arrow, K. J. (1974). Ensayos sobre economía del bienestar. Vol. 2, México D. F., México: Fondo de Cultura Económica.

Arrow, K. J. (1986). Rationality of self and others in an economic system. Journal of Business, S385-S399.

Arrow, K. J. (1989). Opciones sociales y toma de decisiones mediante criterios múltiples. Madrid, España: Alianza Editorial.

Arrow, K. J. (1994). Social Choice and Allocation Mechanisms. Introduction. En Arnott R., Arrow K., Atkinson A., Dreze J., ed. Public Economics. Selected Papers by William Vickrey, Cambridge University Press.

Arrow, K. J. (1999). Amartya K. sen's contributions to the study of social welfare. The Scandinavian Journal of Economics, 101(2), 163-172.

Ball, R., \& Brown, P. (1968). An empirical evaluation of accounting income numbers. Journal of accounting research, 159-178.

Beck, T., \& Levine, R. (2002). Industry growth and capital allocation: does having a market-or bank-based system matter?. Journal of financial economics, 64(2), 147-180.

Beck, T., \& Levine, R. (2004). Stock markets, banks, and growth: Panel evidence. Journal of Banking \& Finance, 28(3), 423-442.

Beck, T., \& Levine, R. (1999). A new database on financial development and structure (Vol. 2146). World Bank Publications. Recuperado de: http:// www.worldbank.org/research/projects/finstructure/database.htm

Beck, T., Levine, R., \& Loayza, N. (2000). Finance and the Sources of Growth. Journal of financial economics, 58(1), 261-300.

Black, F., \& Scholes, M. (1973). The pricing of options and corporate liabilities. Journal of political economy, 81(3), 637-654.

Brennan, M. J. (1970). Taxes, market valuation and corporate financial policy. National tax journal, 23(4), 417-427.

Buchanan, J. (1954). Social Choice, Democracy, and Free Markets. Journal of Economic Literature. Xxxiv, 669-700.

Buchanan, J., \& Tullock, G. (eds.). (1962). Calculus of Consent. En español: El cálculo del consenso. Madrid, España: Espasa-Calpe 1982. 
Buchanan, J., \& Tollison, R. (eds.). (1972). Theory of Public Choice. University of Michigan Press.

Campos, P., \& Sáez Gómez, J. M. (1998). La evolución histórica de la salud pública. En: Martínez Navarro, F., Antó, J. M., Castellanos, P. L., Gili, M., Marset, P., \& Navarro, V. México D. F., México: Salud Pública.

Canguilhem, G. (1971). Ideología y racionalidad en la historia de las ciencias de la vida. Buenos Aires, Argentina: Editorial Amorrortu.

Coase, R. H. (1937). The nature of the firm. Economica, 4(16), 386-405. London School of Economics.

Coase, R. H. (1988). The Firm, the Market and the Law, The Federal Communications Commission. University of Chicago Press, Chicago, Illinois. En español: La empresa, el mercado y la ley. Madrid, España: Alianza Editorial 1994.

Cornell, B., \& Roll, R. (1981). Strategies for pairwise competitions in markets and organizations. The Bell Journal of Economics, 12(1), 201-213.

Dann, L. Y., Mayers, D., \& Raab, R. J. (1977). Trading rules, large blocks and the speed of price adjustment. Journal of Financial Economics, 4(1), 3-22.

DeAngelo, H., \& Masulis, R. W. (1980). Optimal capital structure under corporate and personal taxation. Journal of financial economics, 8(1), 3-29.

Demirgüç-Kunt, A., \& Maksimovic, V. (2002). Funding growth in bank-based and market-based financial systems: evidence from firm-level data. Journal of Financial Economics, 65(3), 337-363.

Demsetz, H. (1968). Why regulate utilities?. The Journal of Law and Economics, $11(1), 55-65$.

Fama, E. F., \& Malkiel, B. G. (1970). Efficient capital markets: A review of theory and empirical work. The journal of Finance, 25(2), 383-417.

Fama, E. F., \& Blume, M. E. (1966). Filter rules and stock-market trading. The Journal of Business, 39(1), 226-241.

Farrar, D. E., Farrar, D. F., \& Selwyn, L. L. (1967). Taxes, corporate financial policy and return to investors. National Tax Journal, 20(4), 444-454.

Finnerty, J. E. (1976). Insiders and market efficiency. The Journal of Finance, 31(4), 1141-1148.

Franco, S. (2011). Los verbos de la salud pública. En: La salud y la vida. Quito. 211-234. Recuperado de: http://www.observatoriorh.org/centro/sites/ default/files/webfiles/fulltext/saludyvida_vol3.pdf.

Friedman, M., (1953). The Methodology of Economics Positive. En Essays in Positive Economics, Chicago University Press. Versión en español: 1986, La metodología de la economía positiva. En: Filosofía y teoría económica. México D. F., México: Fondo de Cultura Económica 1986.

Furtado, C. (1965). Dialéctica del desarrollo. México D. F., México: Fondo de Cultura Económica.

Gordon, M. J. (1963). Optimal investment and financing policy. The Journal of finance, 18(2), 264-272. 
Grossman, S. (1976). On the efficiency of competitive stock markets where trades have diverse information. The Journal of finance, 31(2), 573-585.

Grossman, S. J., \& Stiglitz, J. E. (1976). Information and competitive price systems. The American Economic Review, 66(2), 246-253.

Grossman, S. J., \& Stiglitz, J. E. (1980). On the impossibility of informationally efficient markets. The American economic review, 70(3), 393-408.

Grossman, S. J., \& Hart, O. D. (1986). The costs and benefits of ownership: A theory of vertical and lateral integration. Journal of political economy, 94(4), 691-719.

Guasch, J. L., \& Spiller, P. T. (1999). Managing the regulatory process: design, concepts, issues, and the Latin America and Caribbean story. World Bank Publications.

Hirschman, A. (1980). Les passions et les interets. Presses Universitaires de France. Advancing socio-economics: an institutionalist perspective. Hollingsworth, J. R., Müller, K. H., \& Hollingsworth, E. J. (Eds.). Lanham, MD: Rowman \& Littlefield 2005.

Hirshleifer, J., \& Riley, J. G. (1979). The analytics of uncertainty and information-an expository survey. Journal of economic literature, 17(4), 1375-1421.

Hodgson G. M., (1994). Precursor in Modern Evolutionary Economics: Marx, Marshall, Veblen and Chumpeter. En R. W. England (editor). Evolutionary Concepts in Contemporary Economics. The University of Michigan Press, Ann Arbor, pp. 9-35.

Hodgson, G. M. (1998). The approach of institutional economics. Journal of economic literature, 36(1), 166-192.

Jaffe, J. F. (1974). The effect of regulation changes on insider trading. The Bell Journal of Economics and Management Science, 93-121.

Jensen, M. C., \& Meckling, W. H. (1976). Theory of the firm: Managerial behavior, agency costs and ownership structure. Journal of financial economics, 3(4), 305-360.

Joy, O. M., Litzenberger, R. H., \& McEnally, R. W. (1977). The adjustment of stock prices to announcements of unanticipated changes in quarterly earnings. Journal of Accounting Research, 15(2), 207-225.

King, R. G., \& Levine, R. (1993). Finance and growth: Schumpeter might be right. The quarterly journal of economics, 108(3), 717-737.

Knight, F. (1921). Risk, Uncertainty, and Profit. Boston, MA: Houghton Mifflin Company.

Kraus, A., \& Stoll, H. R. (1972). Price impacts of block trading on the New York Stock Exchange. The Journal of Finance, 27(3), 569-588.

Krieger N. (2003). Epidemiology and the People's Health. Oxford University Press.

Laffont J., \& Tirole J., (1993). A theory of incentives in procurement and regulation. The MIT Press. 
Leland, H. E., Pyle, D. H., \& Brealey, R. (1977). Informational asymmetries, financial structure, and financial intermediation. The journal of Finance, 32(2), 371-387.

Levine, D. K. (1991). Asset trading mechanisms and expansionary policy. Journal of Economic Theory, 54(1), 148-164.

Levine, D. K. (1998). Modeling altruism and spitefulness in experiments. Review of economic dynamics, 1(3), 593-622.

Levine, D. K. (1999). Learning in the Stock Flow Model, in Money, Markets and Method: Essays in Honour of Robert W. Clower, ed. P. Howitt, E. de Antoni and Leijonhufvud, Edward Elgar: Cheltenham, 236-246.

Levine, D. K. (2002). Modeling Altruism and Spitefulness in Experiments, in Critical Studies in Economic Institutions: Trust, ed. G. M. Hodgson and E. L. Khalil, Edward Elgar: Cheltenham, reprinted from Review of Economic Dynamics.

Levine, R., \& Zervos, S. (1998). Stock markets, banks and economic growth. American Economic Review, 88, 537-558.

Lucas, R. (1988). On the Mechanics of Economic Development, Journal of Monetary Economics, 22, 3-42.

Marín, J., \& Rubio, G. (2001). Economía Financiera. Barcelona, España: Antoni Bosch Editor.

Markowitz, H. (1952). Portfolio selection. The journal of finance, 7(1), 77-91.

Marshall, A. (1890). Principles of Economics. McMillan, London. Book V, London. En español: Principios de Economia, Madrid, España: Aguilar 1957.

Ménard, C. (1995). Markets as institutions versus organizations as markets? Disentangling some fundamental concepts. Journal of economic behavior \& organization, 28(2), 161-182.

Merton, R. C. (1973). Theory of rational option pricing. The Bell Journal of economics and management science, 141-183.

Miller, M. H. (1977). Debt and taxes. The Journal of Finance, 32(2), 261-275.

Miller, M. H., \& Modigliani, F. (1961). Dividend policy, growth, and the valuation of shares. The Journal of Business, 34(4), 411-433.

Modigliani, F., \& Miller, M. H. (1958). The cost of capital, corporation finance and the theory of investment. The American economic review, 48(3), 261-297.

Naciones Unidas (1948). Declaración Universal de Derechos Humanos. Recuperado de: www.un.org/es/documents/udhr/

North, D. C. (1990). Institutions, institutional change and economic performance. Cambridge University Press. En español: Instituciones, cambio institucional y desempeño económico. México D. F., México: Fondo de Cultura Económica 1990.

OMS (2002). Informe Mundial sobre el Envejecimiento y la salud. Pp. 3-20. Recuperado de: http://apps.who.int/iris/bitstre am/10665/186466/1/9789240694873_spa.pdf. 
Ostrom, E. (1990). Governing the Commons. The Evolution of Institutions for Collective Action, Political Economy of Institutions and Decisions. Cambridge University Press.

Power, C., \& Kuh, D. (2006). Life course development of unequal health. En: Siegrist, J., \& Marmot, M. Social inequalities in health: new evidence and policy implications.

Rajan, R., \& Zingales, L. (1998). Financial Development and Growth. American Economic Review, 88(3), 559-586.

Rajan, R. G. (1992). Insiders and outsiders: The choice between informed and arm's-length debt. The Journal of Finance, 47(4), 1367-1400.

Robinson J. (1932). Economics is a Serious Subject. Cambridge, UK: W. Heffer \& Sons.

Robinson, J. (1952). The Rate of Interest and Other Essays. Londres, UK: MacMillan.

Ross, S. (1977). Return Risk and Arbitrage. En: Friend, I. \& Bicksler, I. (Eds.), Risk and Return in Finance, Cambridge, MA: Ballinger Press.

Rousseau, P., \& Wachtel, P. (2000). Inflation Financial Development and Growth, Working Papers 00-10, New York University, Leonard N. School of Business, Departament of Economics.

Rubinstein, M. E. (1973). A mean-variance synthesis of corporate financial theory. The Journal of Finance, 28(1), 167-181.

Rawls, J. (1971). A Theory of Justice, The Bleknap Press of Harvard University Press, Cambridge, MA. En español: Teoría de la justicia. México D. F., México: Fondo de Cultura Económica 1979.

Sala-I-Martin, X. (1994). Lecture Notes on Economic Growth, 2a Editions. En español: Apuntes de crecimiento económico. Barcelona, España: Antoni Bosch Editor.

Sharpe, W. F. (1964). Capital asset prices: A theory of market equilibrium under conditions of risk. The Journal of Finance, 19(3), 425-442.

Sen, A. (1976). Elección colectiva y bienestar social. Madrid, España: Alianza Editorial.

Sen, A. (1979). Personal utilities and public judgements: or what's wrong with welfare economics. The Economic Journal, 89(355), 537-558.

Sen A. (1979). Economía del crecimiento, México D. F., México: Fondo de Cultura Económica.

Sen A. (1981). Poverty and Famines: An Essay on Entitlement and Deprivation, Clarendon Press, Oxford.

Sen A. (1982a). Choice, Welfare and Measurement, Harvard University Press, Cambridge.

Sen A. (1982b). Food Batles: Conflict in the Access to Food, Coroman del Lecture. 
Sen, A. (1983a). Liberty and social choice. The Journal of Philosophy, 80(1), 5-28.

Sen, A. (1983b). Los bienes y la gente. Revista de Comercio Exterior, 33(12), 1115-1123.

Sen, A. (1983c). Development: Which Way Now? The Economic Journal, (93), 745-762. En español: ¿Cuál es el camino del desarrollo? Revista de Comercio Exterior, 35(10), 939-949, México 1985.

Sen, A. (1985). Well-being, agency and freedom: The Dewey lectures 1984. The Journal of Philosophy, 82(4), 169-221.

Sen, A. (1987). Freedom of Choice: Concept and Content. Wider Publications, World Institute for Development Economics Research United Nations University. Helsinki.

Sen, A. (1993). Markets and freedoms: achievements and limitations of the market mechanism in promoting individual freedoms. Oxford Economic Papers, 519-541. En español: Mercados y libertades. Logros y limitaciones del mecanismo de mercado en el fomento de las libertades individuales. Bienestar, Justicia y Mercado, 123-156.

Sen, A. (1995). Racionality and Social Choice. American Economic Review, (85), 1-24.

Sen, A. (1997a). El bienestar y la condición de ser agente y la libertad. Conferencias Dewey de 1984, en Bienestar, Justicia y Mercado, Paidós, Barcelona.

Sen, A. (1997b). Human Capital and Human Capacity. World Development, (25). Reproducido en: Cuadernos de Economía, 17(29), 67-72. Bogotá 1998.

Simon, H. A. (1957). Models of Man: Social and Rational. New York, NY: Wiley.

Simon, H. A. (1972). Theories of Bounded Rationality. En C.B: McGuire, R. Redner (editores), Decisión and Organization, North - Holland, Amsterdam, pp. 161-172.

Simon, H. A. (1979). Rational decision making in business organizations. The American economic review, 69(4), 493-513.

Simon, H. A. (1991). Organizations and markets. The Journal of Economic Perspectives, 5(2), 25-44.

Smith, A. (1759). The Theory of Moral Sentiments. New York, NY: Prometheus Books 2000.

Stiglitz, J. (1977). The Theory of Local Public Goods. Feldstein Martin and Inman Robert (eds). The Economics of Public Services, London, UK: MacMillan, pp. 274-333.

Stiglitz, J. (1994). Replanteamiento del papel económico del Estado: Bienes privados suministrados públicamente. Análisis Económico de la Sanidad pp. 19-49., Gillem López Casasnovas, Generalitad de Cataluña, Barcelona, España. 
Stiglitz, J. (1995). Interest Rate Puzzles, Competitive Theory and Capital Constraints. In Economics in a Changing World, IEA Conference Volume, Economic Growth and Capital and Labour markets, 111, Jean-Paul Fitoussi (ed.), New York: St. Martin's Press, 1995, 145-175.

Stiglitz, J. (1997). La economía del sector público. Barcelona, España: Antoni Bosch Editor.

Stiglitz, J. (1998). Toward a New paradigm for Development: Strategies, Policies and processes. Prebisch Lecture at UNTAD, Geneve, October 19.

Tobin, J. (1958). Liquidity preference as behavior towards risk. The Review of Economic Studies, 25(2), 65-86.

Todaro, M. (1985). El desarrollo económico del tercer mundo. Madrid, España: Alianza Editorial.

Train, K. (1994). Optimal Regulation. The Economic theory of Natural Monopoly. The MIT Press.

Tullock, G. (1959). The problem of consensus. The Journal of Political Economy, (67), 571-579. En español: Problemas de la votación mayoritaria. En La economía del bienestar, Tomo I, pp. 215-226. México D. F., México: Fondo de Cultura Económica 1974.

Tullock, G. (1974). The Social Dilemma. University Publications, Blacksburg, Virginia.

Universidad Santo Tomás (2002). Estatuto Orgánico, Bogotá D. C. Recuperado de: http://www.usta.edu.co/documents/generales.pdf.

Universidad Santo Tomás (2004). Proyecto Educativo Institucional -PEI-, Bogotá D. C. Recuperado de: http://www.usta.edu.co/documents/generales.pdf.

Universidad Santo Tomás (2004). Política Curricular para Programas Académicos, Bogotá D. C. Recuperado de: http://www.usta.edu.co/documents/ generales.pdf.

Universidad Santo Tomás (2004). Estatuto Docente. Bogotá D. C. Recuperado de: http://www.usta.edu.co/documents/generales.pdf.

Universidad Santo Tomás (2005). Proyecto de Investigación Institucional -PROIN- Bogotá D. C. Recuperado de: http://www.usta.edu.co/documents/generales.pdf.

Universidad Santo Tomás (2010). Modelo Educativo Pedagógico, Bogotá D. C. Recuperado de: http://www.usta.edu.co/documents/generales.pdf.

Universidad Santo Tomás (2010). Documento Maestro de la Maestría en Protección Social, Bogotá D. C., Colombia: Ediciones USTA.

Universidad Santo Tomás (2016). Plan Integral Multicampus -PIM- 20162027 Bogotá. http://www.usta.edu.co/documents/generales.pdf.

Universidad Santo Tomás (2016). Plan General de Desarrollo 2016-2019 Bogotá. http://www.usta.edu.co/documents/generales.pdf.

Veblen, T. (1899). The Theory of the Leisure Class. Recuperado de: http:// www.gutenberg.org/ebooks/833 
Veblen, T. (1904). The Theory of the Business Enterprise. New Brunswick, NJ: Transaction Books.

Wagner, W. H., \& Lau, S. C. (1971). The effect of diversification on risk. Financial Analysts Journal, 27(6), 48-53.

Walras, L. (1926). Elements of Pure Economics or the Theory of Social Wealth. Philadelphia, PA: Orion 1984.

Watts, R. L. (1978). Systematic 'abnormal'returns after quarterly earnings announcements. Journal of financial Economics, 6(2-3), 127-150.

Williamson, O. E. (1975). Market and Hierarchies. New York, NY: The Free Press.

Williamson, O. E. (1985). The Economic Institutions of Capitalism. New York, NY: The Free Press. En español: Las instituciones económicas del capitalismo, México D. F., México: Fondo de Cultura Económica 1989.

Williamson, O. E. (1988). Corporate finance and corporate governance. The Journal of Finance, 43(3), 567-591.

Williamson, O. E. (1993). Calculativeness, trust, and economic organization. The Journal of Law and Economics, 36(1, Part 2), 453-486.

Williamson, O. E. (1996). The Mechanisms of Governance. Oxford University Press. 


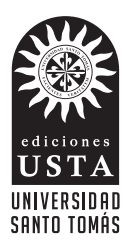

Esta obra se editó en Ediciones USTA,

Departamento Editorial de la Universidad Santo Tomás.

Se usó papel propalcote de 300 gramos para la carátula y papel bond beige de 75 gramos para páginas internas.

Tipografía de la familia Sabón. Impreso por Digiprint. 
Los estudios y los debates sobre la riqueza han sido una constante a lo largo de los siglos. En las sociedades modernas, la manera en que se genera la riqueza y la forma como se acumula e impacta al medio ambiente son temas de primer orden que ocupan la atención de los gobiernos y las comunidades.

El libro que el lector tiene en sus manos hace parte del programa de investigación de la Facultad de Economía sobre riqueza y equidad y su contenido aborda de manera particular la problemática de la vivienda. Sus capítulos contribuyen a una reflexión en torno a la riqueza y la vivienda desde cuatro enfoques analíticos: la economía pública -el ámbito de las políticas públicas-, la economía social - con respecto a la situación socioeconómica de los beneficiarios de la política-, la economía financiera - con énfasis en la especulación y la generación de las burbujas inmobiliarias-, y la economía de las organizaciones - con particular atención al rol de los agentes económicos, estatales y sociales-.

Este es un producto resultado de procesos de consolidación de líneas de investigación del grupo de investigación Economía y Humanismo de la Facultad de Economía de la Universidad Santo Tomás. 